\title{
Propofol suppresses the progression of non-small cell lung cancer via downregulation of the miR-21-5p/MAPK10 axis
}

\author{
XINHUA WU, XUEBIN LI and GUIPING XU \\ Department of Anesthesiology, People's Hospital of \\ Xinjiang Uygur Autonomous Region, Urumqi 830001, Xinjiang UygurAutonomous Region, P.R.China
}

Received December 12, 2019; Accepted April 16, 2020

DOI: $10.3892 /$ or.2020.7619

\begin{abstract}
Non-small cell lung cancer (NSCLC) accounts for $>80 \%$ of lung cancer cases and is the leading cause of cancer-associated mortality worldwide. Propofol is an anesthetic drug frequently used during tumor resection. It is also known to exert inhibitory effects on cancer. Although the role of propofol in NSCLC has been reported, its underlying mechanisms remain unknown. The present study aimed therefore to investigate the mechanisms of propofol action on NSCLC. Starbase V3.0 project was used to analyze the expression levels of microRNA-21-5p (miR-21-5p) and mitogen-activated protein kinase 10 (MAPK10) in NSCLC and adjacent normal tissues from patients with NSCLC and the association between miR-21-5p and MAPK10 expression level in NSCLC tissues. The correlation between MAPK10 expression and disease-free survival (DFS) in patients with NSCLC was analyzed using GEPIA software version 1.0. miR-21-5p and MAPK10 expression in tumor and adjacent normal tissues from patients with NSCLC was evaluated by reverse transcription-quantitative (RT-q) PCR and western blotting. Cell viability and apoptosis were assessed by using Cell Counting Kit-8 assay and flow cytometry, respectively. The interaction between miR-21-5p and MAPK10 was predicted by TargetScan/miRanda and verified by dual luciferase assay. The regulatory effect of propofol on miR-21-5p and MAPK10 expression in NSCLC cell lines was examined by RT-qPCR and western blotting. Starbase V3.0 project and the results of the present study indicated that tumor tissues presented a significantly lower MAPK10 level and a higher miR-21-5p level compared with the normal samples, and that miR-21-5p expression was negatively correlated with MAPK10 expression in the tumor tissues of patients with NSCLC. Furthermore, miR-21-5p targeted the 3 '-untranslated region of MAPK10. In addition, compared
\end{abstract}

Correspondence to: Dr Xuebin Li, Department of Anesthesiology, People's Hospital of Xinjiang Uygur Autonomous Region, 91 Tianchi Road, Urumqi 830001, Xinjiang UygurAutonomous Region, P.R. China E-mail: lixuebinxj@163.com

Key words: lung cancer, propofol, mitogen-activated protein kinase 10, microRNA-21-5p with BEAS-2B cells, a higher miR-21-5p and a lower MAPK10 expression was observed in the NSCLC cell lines A549 and H1299, which was reversed by propofol. The overexpression of miR-21-5p abrogated the effects of propofol on A549 and H1299 cell viability and apoptosis by targeting MAPK10. Taken together, these findings demonstrated that propofol inhibited the viability and promoted the apoptosis of NSCLC cells by downregulating the miR-21-5p/MAPK10 axis.

\section{Introduction}

Lung cancer is the leading cause of cancer-associated mortality worldwide, with $\sim 1.8$ million new cases and 1.2 million mortality cases annually (1). NSCLC accounts for $\sim 80 \%$ of lung cancer cases (2). Advances in the diagnosis and treatment of lung cancer, including percutaneous lung biopsy, tumor marker detection, surgical, medicine and radiological intervention, have been achieved in the last decade (3). However, the 5-year survival rate of patients with lung cancer is only $15 \%$ due to metastasis (4). The development of novel molecular therapies for preventing patient mortality due to metastasis is therefore urgently required (5), which would subsequently improve the current strategies and outcomes.

Propofol is one of the most frequently used intravenous anesthetics during tumor resection due to its rapid onset and short duration of action (6). Propofol was reported to inhibit cancer cell proliferation and migration and cancer invasiveness in various types of cancer, including ovarian (7), breast (8), colon (9) and liver (10) cancers. Considering the widespread use of propofol in clinical practice, exploring the connection between propofol and NSCLC and determining the underlying mechanisms might be essential.

MicroRNAs (miRNAs or miRs) are highly conserved, single-stranded small non-coding RNAs ( 22 nucleotides in length), which inhibit targets post-transcriptionally by binding to their 3'-UTRs (11). miRNAs are involved in numerous biological processes, including cell proliferation, migration, invasion and apoptosis (12). Numerous links between propofol and miRNAs have been reported in NSCLC. For example, propofol has been demonstrated to suppress A549 cell proliferation, migration and invasion by decreasing miR-372 expression (13). In addition, it has been demonstrated that propofol inhibits A549 cell proliferation and epithelial-mesenchymal transition (EMT) by increasing miR-1284 
expression (14), and that it can inhibit H1299 and H1792 cell viability and induce their apoptosis by increasing miR-486 expression (15).

The present study investigated whether the effects of propofol on the viability and apoptosis of A549 and H1299 cells could be mediated by the regulation of another miRNA in particular and its target.

\section{Materials and methods}

Tissue samples. A total of 31 NSCLC tissues and 31 adjacent non-tumor tissues $(5 \mathrm{~cm}$ from tumor tissue) were collected from 31 patients with NSCLC (16 men and 15 women; age range, $40-57$ years; mean age: $47.21 \pm 8.33$ years) who underwent tumor resection at the People's Hospital of Xinjiang Uygur Autonomous Region between February 2015 and January 2017. Patients who had received radiotherapy or chemotherapy prior to the surgery were excluded from the study. The tumors were staged according to the 8th edition of American Joint Committee on Cancer Tumor-Node-Metastasis (TNM) system (16). This study was approved by the Ethics Committee of People's Hospital of Xinjiang Uygur Autonomous Region. Patients provided written informed consent.

Bioinformatics analysis. The interaction between miR-21-5p and MAPK10 was predicted by TargetScan/miRanda. Starbase V2.0 project (http://starbase.sysu.edu.cn/) was used for the analysis of miR-21-5p and MAPK10 expression levels in NSCLC tumor and normal tissues, and the relation between miR-21-5p and MAPK10 in NSCLC tumor tissues from The Cancer Genome Atlas (TCGA) datasets (TCGA-LUAD and TCGA-LUSC) (17).

Survival analysis. GEPIA software version 1.0 developed by Zhang Laboratory at the Peking University was used for the survival analysis based on TCGA data (960 patients) (18). Long-rank test was used to perform the analysis. For group cutoff, MAPK10 median expression threshold was chosen to split the cohort between high expression and low expression. $\mathrm{P}<0.05$ was used for significance threshold.

Cell lines. The human NSCLC cell lines A549 and H1299 and the human lung epithelial cell line BEAS-2B were purchased from the American Type Culture Collection. Cells were cultured in RPMI-1640 medium supplemented with $10 \%$ fetal bovine serum (HyClone; GE Healthcare Life Sciences) and $1 \%$ penicillin/streptomycin (Invitrogen; Thermo Fisher Scientific, Inc.) and placed at $37^{\circ} \mathrm{C}$ in a humidified incubator containing $5 \% \mathrm{CO}_{2}$.

Cell transfection. miR-21-5p mimic and negative control (NC) were synthesized by Shanghai GenePharma Co., Ltd. pcDNA3-MAPK10 and pcDNA3 were purchased from

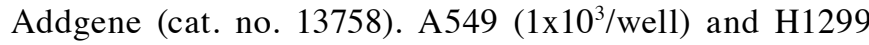
( $1 \times 10^{3} /$ well) cells were seeded in 96-well plates, cultured for $24 \mathrm{~h}$ and transfected with $50 \mathrm{nM}$ miR-21-5p mimic, $50 \mathrm{nM}$ miR-NC mimic, $2 \mu \mathrm{g}$ pcDNA3 or $2 \mu \mathrm{g}$ pcDNA3-MAPK10 using Lipofectamine 2000 reagent (Invitrogen; Thermo Fisher Scientific, Inc.) according to the manufacturer's instructions.
After 48 h, A549 and H1299 cells were collected for subsequent experiments.

Cell treatment. A549 and $\mathrm{H} 1299$ cells were treated with $8 \mu \mathrm{g} / \mathrm{ml}$ propofol (Sigma-Aldrich; Merck KGaA) for $48 \mathrm{~h}$ as previously described (13). Following propofol treatment for $48 \mathrm{~h}$, and/or transfection with miR-21-5p mimic and/or pcDNA3-MAPK10 for $48 \mathrm{~h}$, the A549 and H1299 cells were harvested for use in subsequent experiments.

CCK-8 assay. Cell viability was determined using a Cell Counting Kit-8 (CCK-8; Dojindo Molecular Technologies, Inc.). Briefly, A549 and $\mathrm{H} 1299$ cells $\left(5 \times 10^{3}\right.$ cells/well) were seeded into 96 -well plates. Following propofol treatment and/or transfection with miR-21-5p mimic and/or pcDNA3-MAPK10 for $48 \mathrm{~h}, 10 \mu \mathrm{l} \mathrm{CCK}-8$ solution was added to each well. Plates were then incubated for 1 at $37^{\circ} \mathrm{C}$ in a humidified incubator containing $5 \% \mathrm{CO}_{2}$. Absorbance was read at $450 \mathrm{~nm}$ using a microplate reader (Bio-Rad Laboratories, Inc.).

Cell apoptosis assay. Cell apoptosis was determined using an Annexin-V/Dead Cell Apoptosis kit (cat. no. V13242; Invitrogen; Thermo Fisher Scientific, Inc.). Briefly, A549 $\left(1 \times 10^{6}\right.$ cells $\left./ \mathrm{ml}\right)$ and $\mathrm{H} 1299$ cells $\left(1 \times 10^{6}\right.$ cells $\left./ \mathrm{ml}\right)$ were diluted in $100 \mu \mathrm{l}$ binding buffer. Subsequently, Annexin V (5 $\mu \mathrm{l})$ and propidium iodide $(1 \mu \mathrm{l})$ were added to the cell suspensions. A549 and H1299 cells were then incubated in the dark at room temperature for $15 \mathrm{~min}$. Subsequently, the cell apoptosis rate was determined by flow cytometric analysis using a FACSCalibur flow cytometer (BD Biosciences). Results were analyzed using FlowJo software (version 10.2; FlowJo LLC).

$R N A$ isolation and reverse transcription-quantitative (RT- $q)$ $P C R$. Total RNA was extracted from NSCLC and adjacent tissues, and from the BEAS-2B, A549 and H1299 cells using TRIzol reagent (Thermo Fisher Scientific, Inc.). miRNA was extracted from NSCLC and adjacent tissues, and from the BEAS-2B, A549 and H1299 cells using a miRNA Extraction kit (cat. no. 217004; Qiagen $\mathrm{GmbH}$ ). RNA integrity was determined using a Nano Drop ND-1000 spectrophotometer. RT was carried out using a miRNA cDNA Synthesis kit (Qiagen $\mathrm{GmbH}$ ) and TransScript First-Strand cDNA Synthesis SuperMix (Beijing TransGen Biotech co., ltd.). qPCR was carried out using SYBR-Green Premix Ex Taq II (Qiagen $\mathrm{GmbH}$ ) with the ABI Prism 7500 Sequence Detection system (Applied Biosystems; Thermo Fisher Scientific, Inc.). qPCR reactions were performed as follows: Initial denaturation at $95^{\circ} \mathrm{C}(10 \mathrm{~min})$, then $95^{\circ} \mathrm{C}(5 \mathrm{sec}), 63^{\circ} \mathrm{C}(30 \mathrm{sec})$ and $72^{\circ} \mathrm{C}(30 \mathrm{sec})$ for 40 cycles, followed by an extension step at $72^{\circ} \mathrm{C}(5 \mathrm{~min})$. The sequences of the primers were as followed: MAPK10, forward 5'-CTTCCCAGATTCCCTCTTCC-3', reverse 3'-GCT GGGTCATACCAGACGTT-5'; GAPDH, forward 5'-GAG TCAACGGATTTGGTCGT-3', reverse 3'-TTGATTTTGGAG GGATCTCG-5'; miR-193-3p, forward 5'-ACACTCCAGCTG GGAACTGGCCTACAAAGT-3', reverse 3'-TGGTGTCGT GGAGTCG-5'; miR-221-3p, forward 5'-CUUUGGGUCGUC UGUUACAUCGA-3', reverse 3'-AUUGCUUCUCUUCAU GCAAGUCA-5'; miR-203a-3p, forward 5'-GAUCACCAG GAUUUGUAAAGU-3', reverse 3'-GCAAAUUAAAUUUGG GCUUGUUCU-5'; miR-22-3p, forward 5'-UGUCAAGAA 
GUUGACCGUCGAA-3' and reverse, 3'-AUGGUUGUU UCAAAUGCAUUGGG-5'; miR-125-5p, forward 5'-AGU GUUCAAUCCCAGAGUCCCU-3', reverse 3'-CAGGCUUCA UGAUGUCUCCAUAUGAA-5'; miR-21-5p, forward 5'-AGU UGUAGUCAGACUAUUCGAU-3', reverse 3'-CUUUAC GAUGAAUUCAUUUCC-5'; U6, forward 5'-CGCTTCGGC AGCACATATACTAA-3' and reverse 3'-TATGGAACGCTT CACGAATTTGC-5'. GAPDH was used as the endogenous control for MAPK10. U6 was used as the endogenous control for miR-21-5p. The expression levels of genes were calculated using the $2^{-\Delta \Delta C \mathrm{Cq}}$ method (19).

Western blotting. Proteins were extracted from NSCLC and adjacent tissues, and from the BEAS-2B, A549 and H1299 cells using RIPA lysis buffer (Beyotime Institute of Biotechnology) that contains protease inhibitors (Roche Diagnostics) on ice for $30 \mathrm{~min}$. Following the quantification of protein concentration using BCA (Beyotime Institute of Biotechnology), proteins ( $20 \mu \mathrm{g} / \mathrm{lane}$ ) were separated by $8 \%$ SDS-PAGE and transferred onto PVDF membranes. Membranes were blocked with 5\% non-fat milk for $2 \mathrm{~h}$ at room temperature and were incubated with primary antibodies against BAX (cat. no. 2772; 1:1,000), Bcl-2 (cat. no. 4223; 1:1,000), MAPK10 (cat. no. 2305; $1: 1,000)$ and GAPDH (cat. no. $5174 ; 1: 1,000)$ at $4^{\circ} \mathrm{C}$ overnight. Membranes were then incubated with goat-anti rabbit secondary antibody (cat. no. 7074; 1:2,000; Cell Signaling Technology, Inc.) at room temperature for $2 \mathrm{~h}$. All antibodies were purchased from Cell Signaling Technology, Inc. Bands were detected using enhanced chemiluminescence substrate (EMD Millipore). The band intensities were analyzed using Image $\mathrm{Lab}^{\mathrm{TM}}$ (version 4.0; Bio-Rad Laboratories, Inc.).

Dual-luciferase reporter assay. The binding between miR-21-5p and the 3'-UTR of MAPK10 was predicted by TargetScan version 7.1 (http://www.targetscan.org/vert_71/) and validated by dual-luciferase reporter assay. The 3'-UTR of MAPK10 mRNA was amplified from the cDNA, which was obtained from 293T cells, and inserted into the pGL3-basic vector (Promega Corporation) between the KpnI and Xhol restriction enzyme sites. Two site mutations were introduced into the pGL3-MAPK10 3'-UTR-wild-type (WT) sequence to obtain the pGL3-MAPK10 3'-UTR-Mutant (MT) sequence by using a Quick Site-directed mutation kit (cat. no. 200518; Agilent Technologies, Inc.). $293 \mathrm{~T}$ cells $\left(1 \times 10^{5} /\right.$ well $)$ were plated in 24-well plates, co-transfected with pGL3-MAPK10 3'-UTR-WT (0.4 mg) or pGL3-MAPK10 3'UTR-MT (0.4 mg) together with miR-NC mimic $(20 \mathrm{nM})$ or miR-21-5p mimic $(20 \mathrm{nM})$ using Lipofectamine 2000 (Invitrogen; Thermo Fisher Scientific, Inc.) according to the manufacturer's instructions. After $48 \mathrm{~h}$, the relative luciferase activity in each group was determined using the dual luciferase reporter system kit (Promega Corporation). Renilla luciferase activity (Promega Corporation) acted as the reference control.

Statistical analysis. Each experiment was repeated at least three times in the present study. Statistical analysis was carried out using GraphPad Prism 7.0 software (GraphPad Software, Inc.). Differences between two groups were analyzed by Student's t-test, and differences among three or more groups were analyzed by one-way analysis of variance followed by
Newman-Keuls test. The association between MAPK10 expression and the clinicopathological characteristics of patients was analyzed using $\chi^{2}$ test. Pearson's correlation test was performed to analyze the correlation between the miR-21-5p and MAPK10 mRNA levels. $P<0.05$ was considered to indicate a statistically significant difference.

\section{Results}

Propofol decreases viability and induces apoptosis in NSCLC cell lines. The results from CCK-8 assay demonstrated that propofol significantly decreased A549 and H1299 cell viability compared with control group (Fig. 1A and B). Furthermore, results from flow cytometry indicated that propofol significantly increased NSCLC cell apoptosis compared with control group (Fig. 1C and D). In addition, western blotting analysis revealed that $\mathrm{BAX} / \mathrm{Bcl}-2$ ratio was significantly increased in NSCLC cells following propofol treatment, which was consistent with induction of cell apoptosis (Fig. 1E and F).

Propofol increases MAPK10 expression in NSCLC cell lines. The levels of apoptotic-related molecules were examined following propofol treatment. As an important pro-apoptotic gene (20), a decrease in MAPK10 expression has been reported in breast, gastric, hepatocellular carcinoma and nasopharyngeal carcinomas $(21,22)$. However, to the best of our knowledge, the effects of propofol on MAPK10 expression in NSCLC remain unknown, which was investigated in the present study. In the present study, propofol significantly increased MAPK10 mRNA and protein expression in A549 and H1299 cells compared with control group (Fig. 2A-C).

MAPK10 expression is decreased in NSCLC cell lines and tumor tissues. To the best of our knowledge, expression profile of MAPK10 in NSCLC remains unknown. In the present study, results from RT-qPCR and western blotting demonstrated that MAPK10 mRNA (Fig. 3A) and protein expression (Fig. 3B and C) was significantly lower in the human NSCLC cell lines A549 and H1299 compared with the human lung epithelial cell line BEAS-2B.

The expression profile of MAPK10 in NSCLC was subsequently identified via Starbase V2.0 project. The database showed that compared with the 56 normal samples, MAPK10 expression was significantly lower in the 526 tumor samples with lung adenocarcinoma (TCGA-LUAD; Fig. 3D). Compared with the 49 normal samples, MAPK10 expression was significantly lower in the 501 tumor samples with lung squamous cell carcinoma (TCGA-LUSC; Fig. 3E). In addition, MAPK10 mRNA and protein levels were significantly lower in tumor tissues from patients with NSCLC compared with adjacent normal tissues (Fig. 3F-H). These findings suggested that MAPK10 may serve a tumor-suppressive role in NSCLC.

Propofol decreases miR-21-5p expression in NSCLC cell lines. The present study aimed to determine the oncogenes that target MAPK10. By using the online softwares miRanda and TargetScan, it was found that the 3'UTR of MAPK10 included the complementary sites for 21 miRNAs 
A

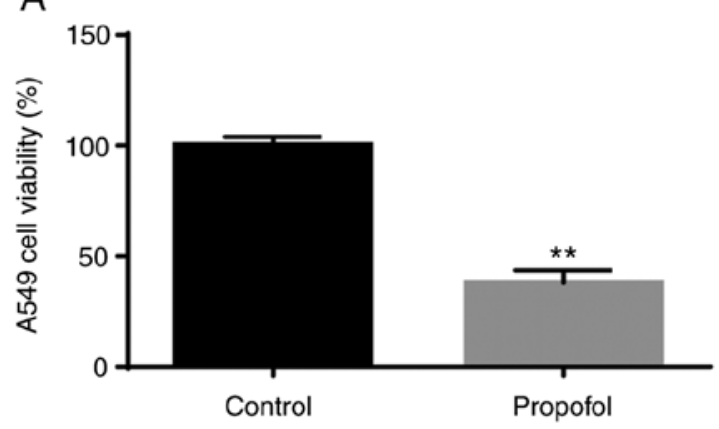

C

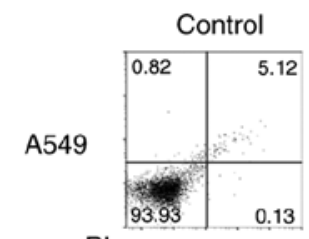

$\mathrm{PI}$
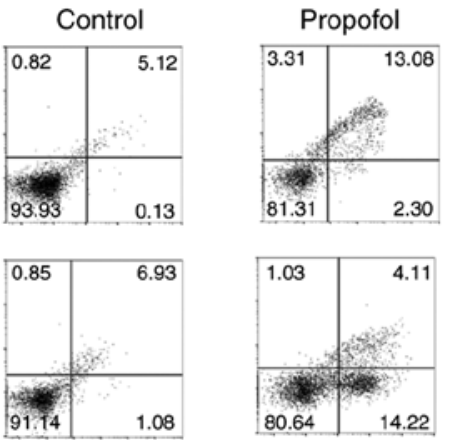

ANNEXIN-V

E

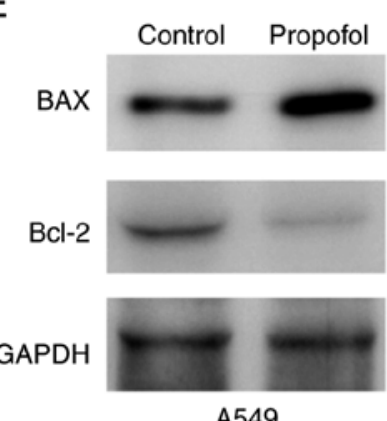

A549
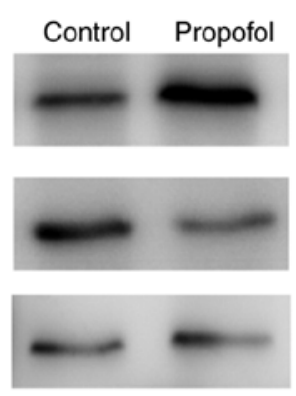

H1299

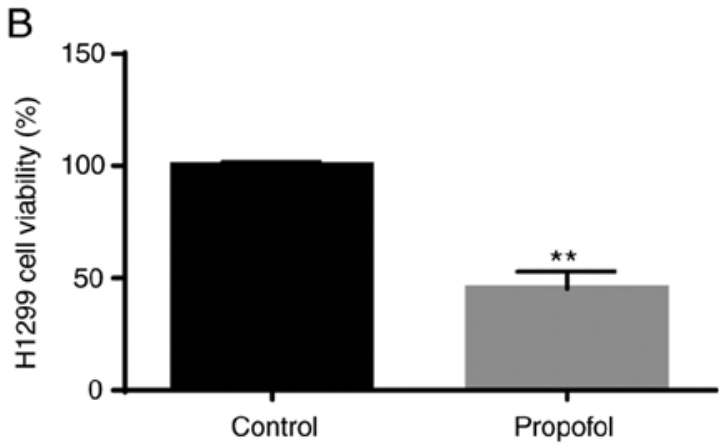

D

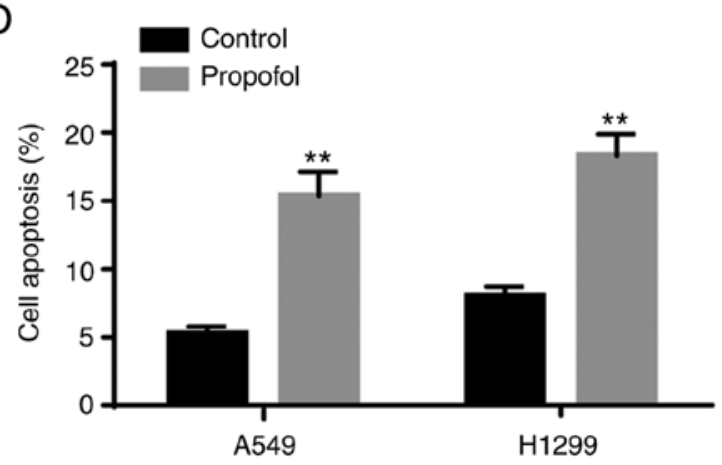

$\mathrm{F}$

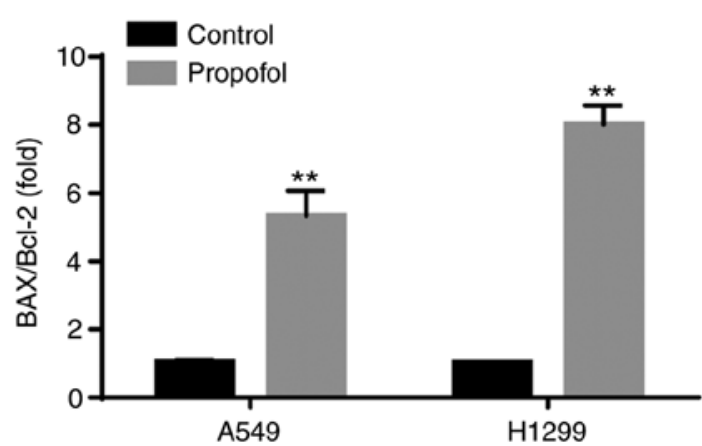

Figure 1. Propofol decreased viability and increased apoptosis of A549 and H1299 cells. (A and B) Compared with control group, results from Cell Counting Kit-8 assay demonstrated that propofol significantly decreased the cell viability. (C and D) Flow cytometry results showed that propofol significantly increased cell apoptosis. (E and F) Western blotting showed that propofol significantly increased BAX protein expression and decreased Bcl-2 protein expression. ${ }^{* *} \mathrm{P}<0.01$ propofol vs. control.
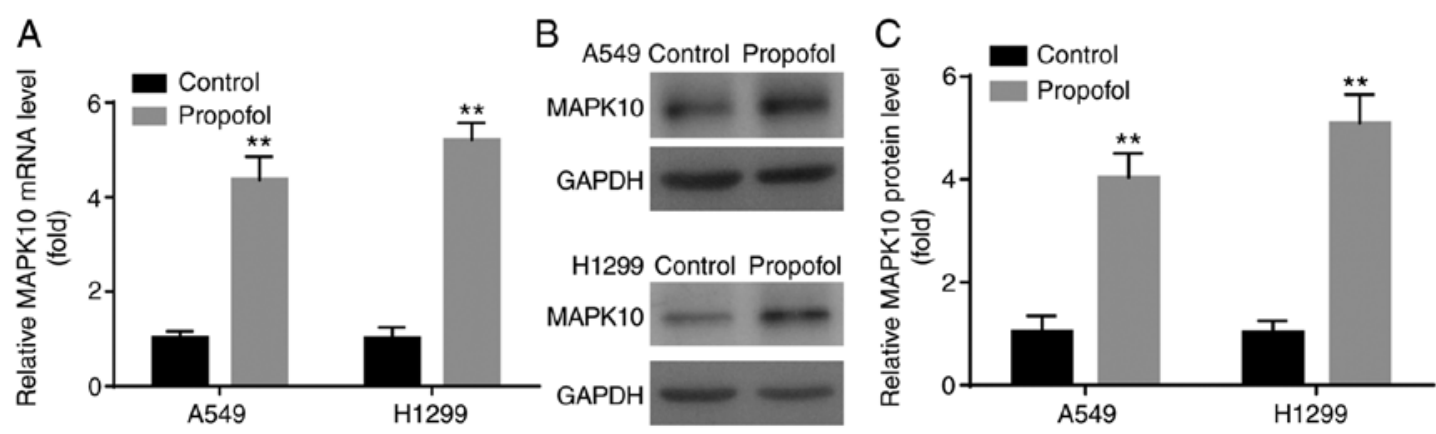

Figure 2. Propofol up-regulated MAPK10 expression level in A549 and H1299 cells. Compared with control group, propofol significantly increased MAPK10 (A) mRNA and (B and C) protein expression. ${ }^{* *} \mathrm{P}<0.01$ propofol vs. control. MAPK10, mitogen-activated protein kinase 10.

in miRanda and 15 miRNAs in TargetScan, and that six miRNAs overlapped, including miR-193-3p, miR-203a-3p, miR-22-3p, miR-125-5p, miR-221-3p and miR-21-5p (Fig. 4A).
Compared with the control group, propofol had no effect on miR-193-3p or miR-203a-3p expression level in A549 and H1299 cells; however, propofol treatment significantly increased miR-221-3p expression level in A549 cells and 

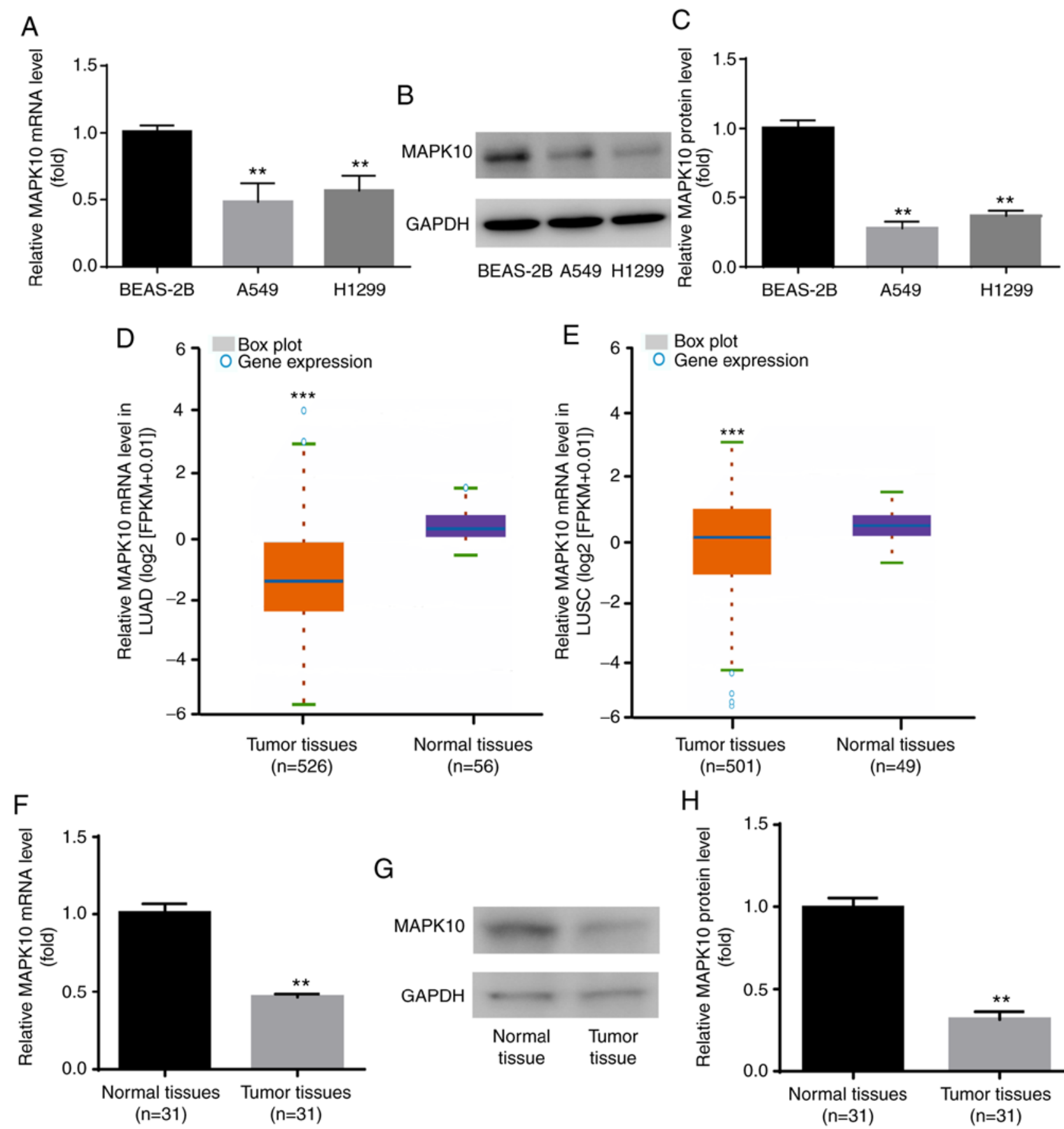

G

$\mathrm{H}$
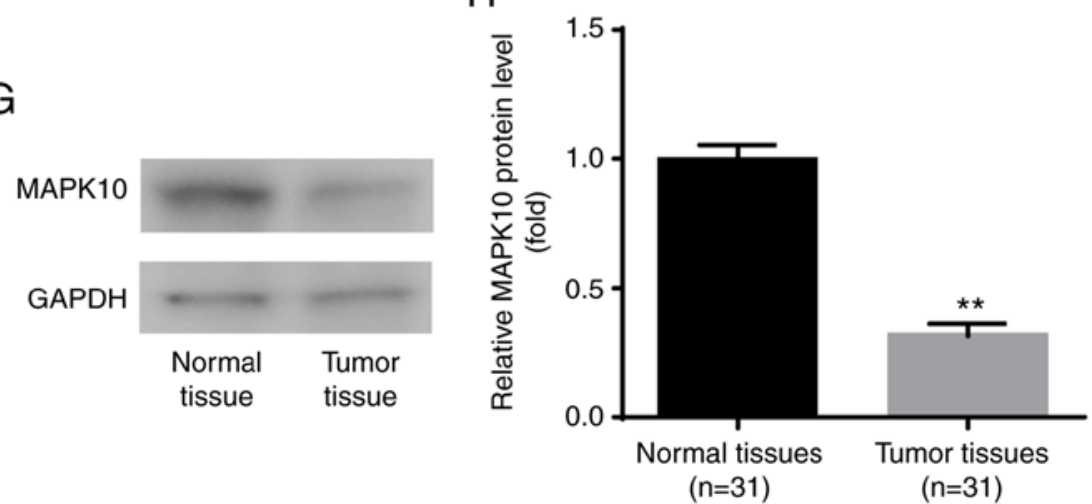

Figure 3. MAPK10 expression was decreased in A549 and H1299 cells and NSCLC tumor tissues. Compared with BEAS-2B cells, MAPK10 (A) mRNA and (B and C) protein expression was significantly decreased in A549 and H1299. (D-H) Compared with normal samples, MAPK10 expression was significantly decreased in NSCLC tissues, according to data from Starbase V3.0 project, reverse transcription quantitative PCR and western blotting. ${ }^{* *} \mathrm{P}<0.01, \mathrm{~A} 549$, H1299 vs. BEAS-2B and tumor tissues vs. normal tissues; ${ }^{* * *} \mathrm{P}<0.001$, tumor tissues vs. normal tissues. MAPK10, mitogen-activated protein kinase 10; LUAD, lung adenocarcinoma; LUSC, lung squamous cell carcinoma.

significantly decreased miR-221-3p expression level in H1299 cells. In addition, propofol significantly increased miR-22-3p expression level in A549 cells; however, it had no effect on miR-22-3p expression level in H1299 cells. Furthermore, propofol treatment significantly decreased and increased miR-125-5p level in A549 and H1299 cells, respectively. However, treatment with propofol downregulated miR-21-5p expression level in both A549 and H1299 cells (Fig. 4B and C). miR-21-5p was therefore selected in the present study and its role in NSCLC was further investigated.
miR-21-5p targets and inhibits MAPK10 expression in NSCLC cell lines. The binding site between MAPK10 and miR-21-5p is illustrated in Fig. 5A. Before exploring the interaction between MAPK10 and miR-21-5p by dual-luciferase reporter assay, the present study aimed to verify the successful transfection of miR-21-5p mimic in A549 and H1299 cells. The results demonstrated a significantly higher miR-21-5p expression level in the miR-21-5p mimic group compared with the miR-NC group, confirming the successful transfection (Fig. 5B). Furthermore, results from dual-luciferase reported assay demonstrated that 


\section{A}

miR-148b, miR-152 miR-222, miR-193b miR-125b, miR-208a miR-495, miR-590-5p miR-335, miR-590-3p miR-599, miR-499-5p miR-148a, miR-125a-3p miR-208b

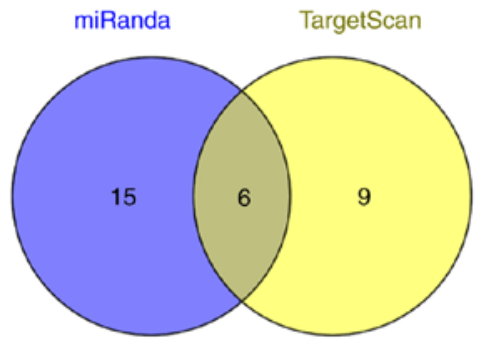

$\operatorname{miR}-7-5 p$ miR-383-5p miR-137 $\mathrm{miR}-129-3 p$ miR-135-5p miR-27-3p miR-128-3p miR-29-3p miR-124-3p
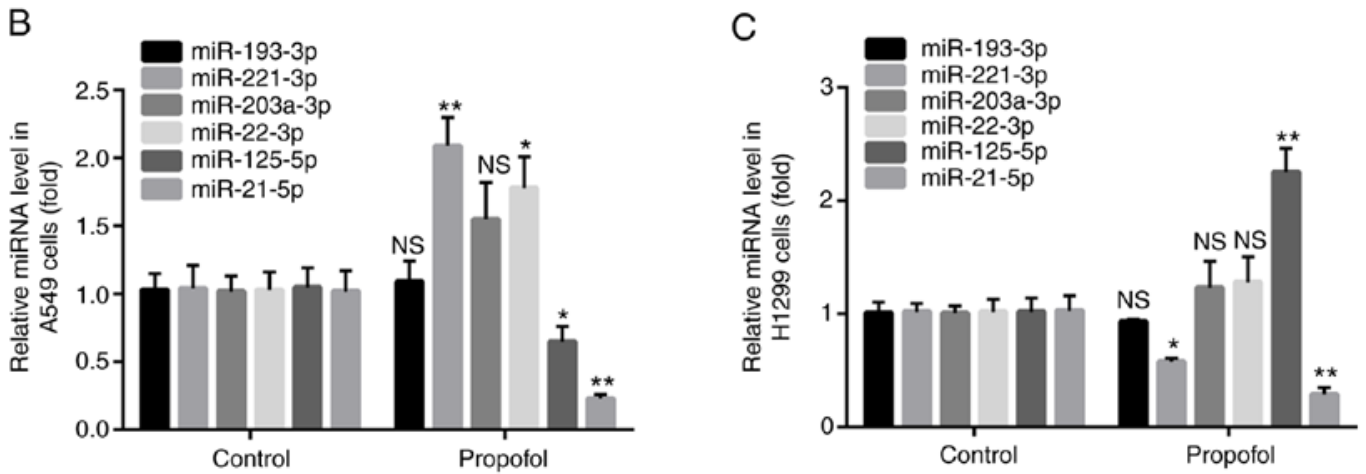

Figure 4. Propofol reduced miR-21-5p expression in A549 and H1299. (A) Six miRNAs overlapped in miRanda and TargetScan. (B and C) Compared with control group, propofol decreased miR-21-5p expression level in A549 and H1299 cells. ${ }^{*} \mathrm{P}<0.05,{ }^{* * *} \mathrm{P}<0.01$ propofol vs. control. NS, not significant; miRNA, microRNA.

A Position 604-610 of MAPK10 3'UTR 5'...AUAUAUUGCCAGUAU-AUAAGCUG..
hsa-miR-21-5p 3'-AGUUGUAUUCAGACUAUUCGAU Position 604-610 of MAPK10 3'UTR 5'...AUAUAUUGCCAGUAU-AUCCGCUG.

\section{C}

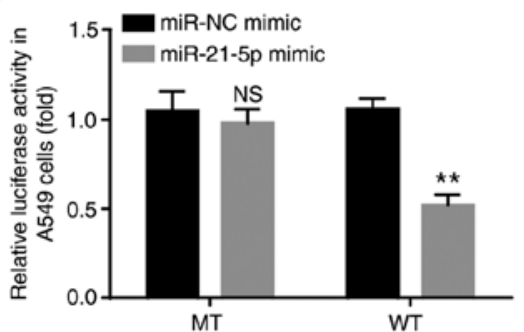

$\mathrm{E}$

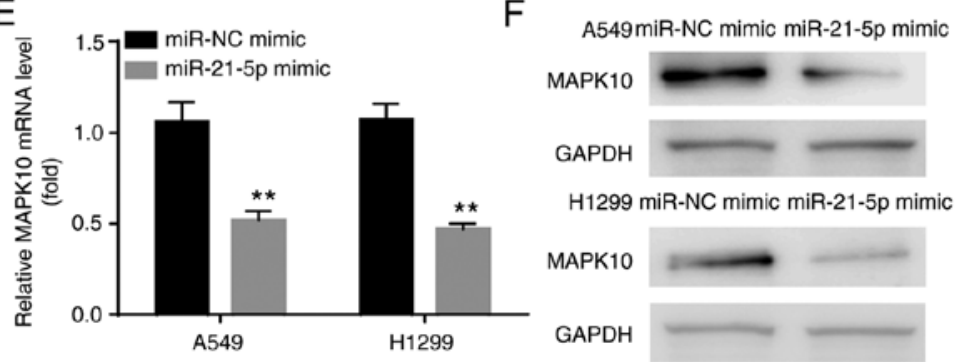

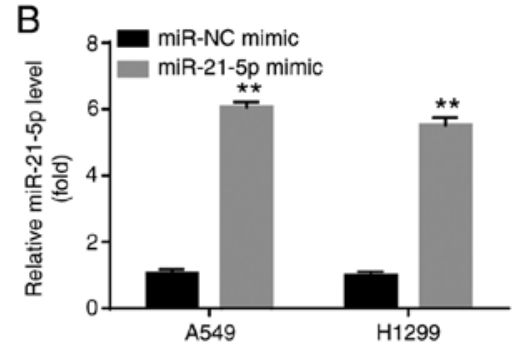
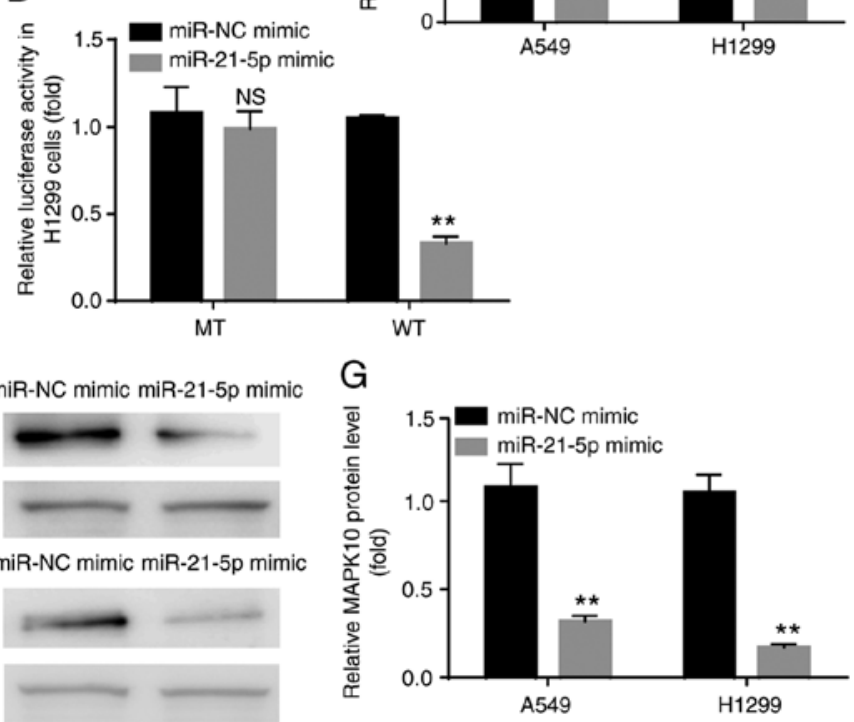

Figure 5. miR-21-5p targeted and inhibited MAPK10 expression in A549 and H1299 cells. (A) Binding site between MAPK10 and miR-21-5p from TargetScan version 7.1. (B) miR-21-5p mimic increased miR-21-5p expression level in A549 and H1299 cells (C and D) miR-21-5p targeted 3'UTR of MAPK10, and inhibited MAPK10 (E) mRNA and (F and G) protein expression in A549 and H1299 cells. ${ }^{* *}$ P<0.01, miR-21-5p mimic vs. miR-NC mimic. NS, not significant; miR, microRNA; NC, negative control; MAPK10, mitogen-activated protein kinase 10.

miR-21-5p mimic inhibited the relative luciferase activity in cells transfected with WT-MAPK10 but not with MT-MAPK10 in A549 and H1299 cells (Fig. 5C and D).
In addition, compared with the miR-NC mimic group, miR-21-5p mimic significantly inhibited the mRNA and protein levels of MAPK10 in A549 and H1299 cells (Fig. 5E-G). 
A
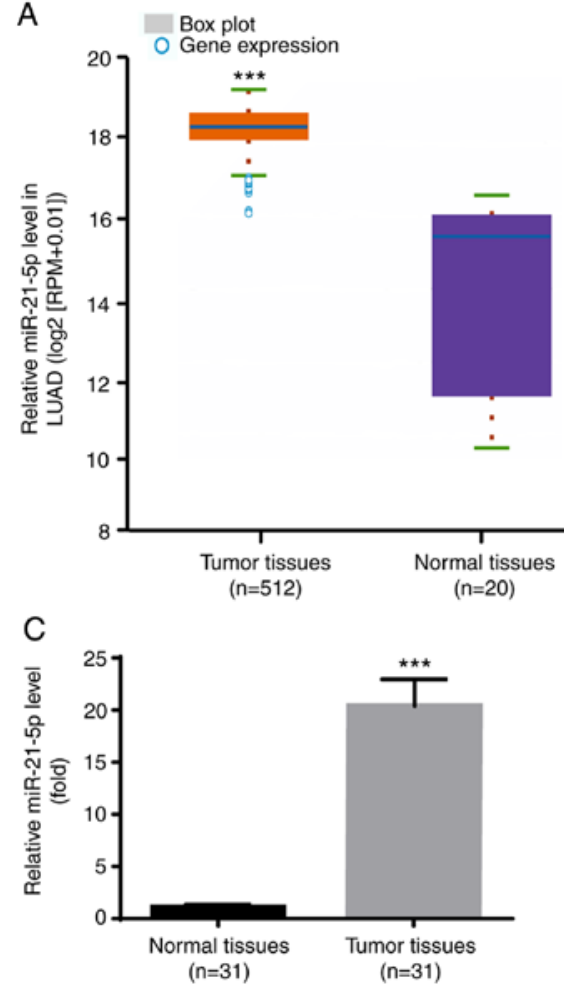

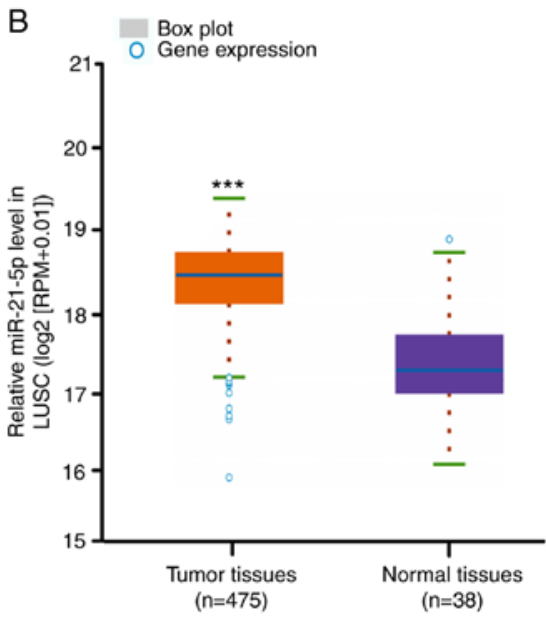

$\mathrm{D}$

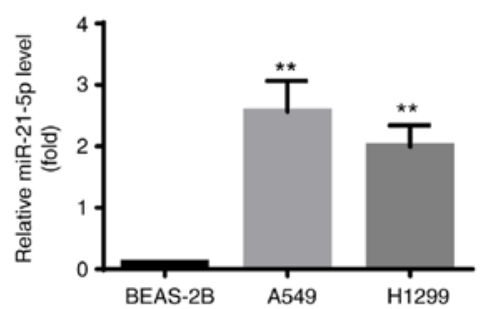

Figure 6. miR-21-5p was increased in A549 and H1299 cells and NSCLC tumor tissues. (A-C) Compared with normal tissues, miR-21-5p level was upregulated in NSCLC tumor tissues from Starbase V3.0 project. (D) Compared with BEAS-2B, miR-21-5p level was upregulated in A549 and H1299 cells. ** P<0.01, A549 or H1299 vs. BEAS-2B; ${ }^{* * *} \mathrm{P}<0.001$, tumor tissues vs. normal tissues. miR, microRNA; LUAD, lung adenocarcinoma; LUSC, lung squamous cell carcinoma.
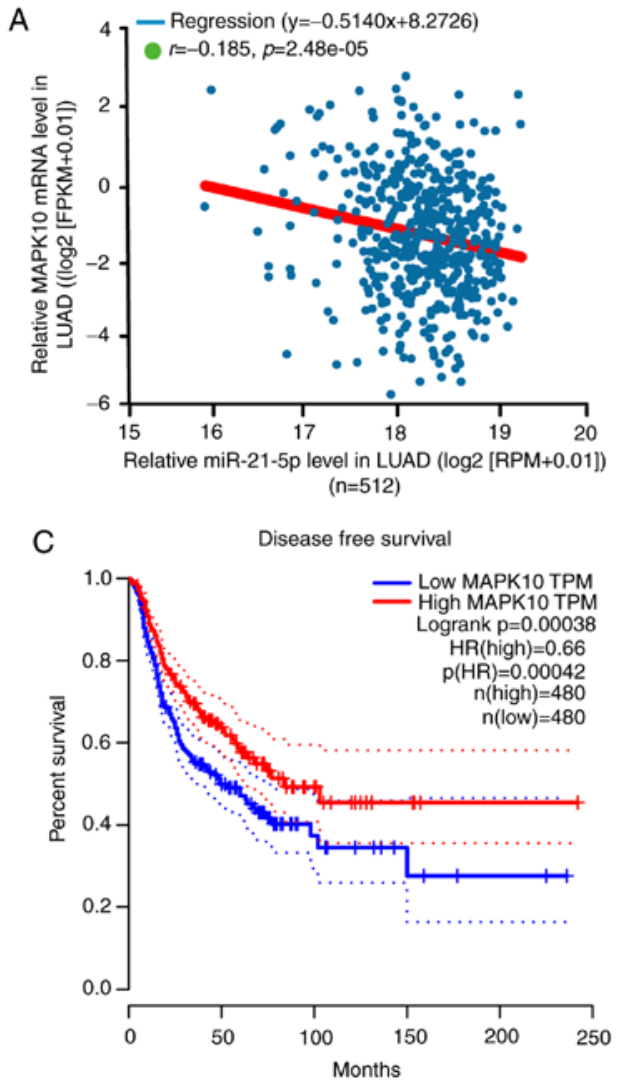
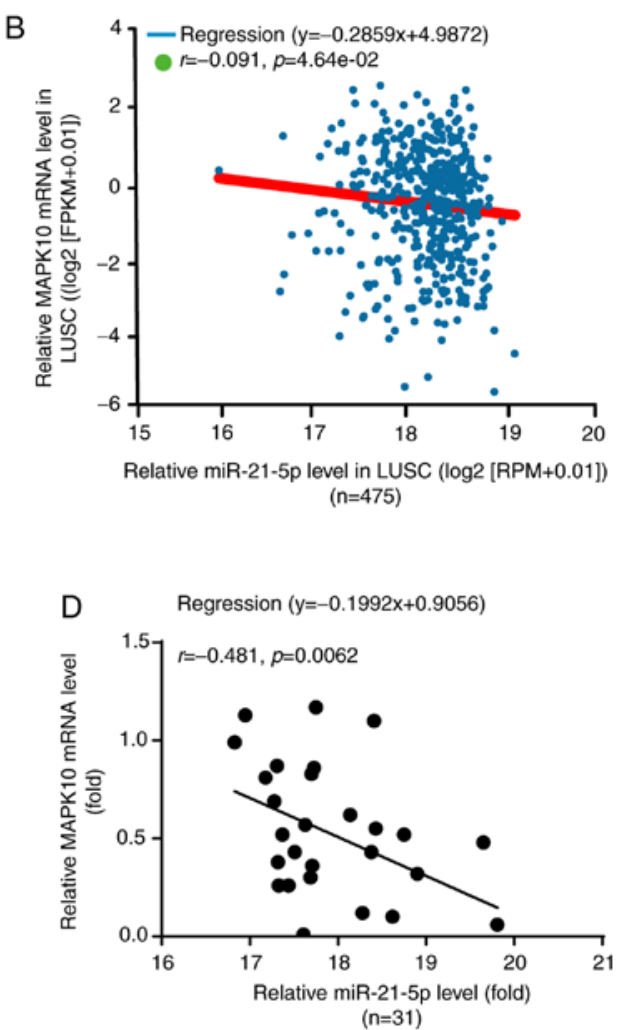

Figure 7. miR-21-5p negatively regulated MAPK10 expression in NSCLC tumor tissues. (A and B) Negative correlation between miR-21-5p and MAPK10 expression in NSCLC tumor tissues from Starbase V3.0 project. (C) MAPK10 level was associated with prolonged disease-free survival in patients with NSCLC from the data of GEPIA software version 1.0. (D) Negative correlation between miR-21-5p and MAPK10 expression in NSCLC tumor tissues form the present study. MAPK10, mitogen-activated protein kinase 10; LUAD, lung adenocarcinoma; LUSC, lung squamous cell carcinoma; TPM, transcription per million value; HR, harzard ratio. 
miR-21-5p is increased in NSCLC cell lines and tumor tissues. The expression profile of miR-21-5p in NSCLC was identified via Starbase V3.0 project. As presented in Fig. 6A, miR-21-5p expression level was significantly increased in the 521 tumor tissues compared with the 20 normal samples in LUAD. Furthermore, as presented in Fig. 6B, miR-21-5p expression level was also significantly increased in the 475 tumor tissues compared with the 38 normal samples in LUSC.

Consistently, miR-21-5p expression level was higher in tumor tissues compared with adjacent normal tissues from the patients with NSCLC included in the present study (Fig. 6C). Furthermore, results from RT-qPCR demonstrated that miR-21-5p expression level was significantly increased in the human NSCLC cell lines A549 and H1299 compared with the human lung epithelial cell line BEAS-2B (Fig. 6D). Taken together, these results further indicated that miR-21-5p may act as an oncogene in NSCLC.

miR-21-5p negatively regulates MAPK10 expression in NSCLC tumor tissues. According to the results from Starbase V3.0 project, there was a negative correlation between miR-21-5p and MAPK10 expression in LUAD $(n=512)$ and LUSC $(n=475)$ (Fig. 7A and B). Furthermore, miR-21-5p is known to be associated with the DFS of patients with NSCLC (23). Subsequently, results from GEPIA software analysis demonstrated that a higher MAPK10 expression ( $\mathrm{n}=480)$ was significantly associated with the prolonged DFS of patients with NSCLC in LUAD and LUSC, which was not the case for patients with lower MAPK10 expression (n=480; Fig. 7C).

Furthermore, miR-21-5p expression was negatively correlated with MAPK10 expression in the tumor tissues of patients with NSCLC included in the present study (Fig. 7D). In addition, the characteristics of patients with NSCLC are presented in Table I, and MAPK10 expression was demonstrated to be significantly associated with lymph node metastasis and Tumor-Node-Metastasis stage; however, MAPK10 expression was not associated with sex, age, histological type, EGFR mutation or KRAS mutation.

Subsequently, the present study investigated whether the effects of propofol on NSCLC cell viability and apoptosis were associated with miR-21-5p and MAPK10 expression. A549 and H1299 cells were therefore randomly divided into four different groups, including the control group, propofol group, propofol + miR-21-5p mimic group and the propofol + miR-21-5p mimic + pcDNA3-MAPK10 group.

Propofol decreases NSCLC cell viability via the miR-21-5p/MAPK10 axis. In A549 and H1299 cells, increased expression of MAPK10 mRNA and protein was confirmed following transfection with pcDNA3-MAPK10 (Fig. 8A-C). Furthermore, results from CCK- 8 assay demonstrated that transfection with miR-21-5p mimic attenuated the propofol-induced decrease in cell viability, which was reversed by pcDNA3-MAPK10 (Fig. 8D and E).

PropofolinducesNSCLC apoptosis viathemiR-21-5p/MAPK10 axis. The results from flow cytometric assay demonstrated that transfection with miR-21-5p mimic attenuated the propofol-induced increase in A549 and H1299 cell apoptosis, which was reversed by pcDNA3-MAPK10 (Fig. 9A and B). In
Table I. Association between MAPK10 expression and the characteristics of patients with NSCLC $(n=31)$.

\begin{tabular}{|c|c|c|c|}
\hline \multirow[b]{2}{*}{ Characteristics } & \multicolumn{2}{|c|}{$\begin{array}{l}\text { MAPK10 } \\
\text { expression }\end{array}$} & \multirow[b]{2}{*}{ P-value } \\
\hline & High & Low & \\
\hline Sex & & & 0.724 \\
\hline Male & 9 & 7 & \\
\hline Female & 7 & 8 & \\
\hline Age, years & & & 0.999 \\
\hline$>55$ & 10 & 9 & \\
\hline$\leq 55$ & 6 & 6 & \\
\hline Histological type & & & 0.285 \\
\hline Squamous cell carcinoma & 9 & 5 & \\
\hline Adenocarcinoma & 7 & 10 & \\
\hline Lymph node metastasis & & & 0.012 \\
\hline Yes & 12 & 4 & \\
\hline No & 4 & 11 & \\
\hline TNM stage & & & 0.029 \\
\hline I-II & 3 & 9 & \\
\hline III-IV & 13 & 6 & \\
\hline EGFR mutation & & & 0.722 \\
\hline Yes & 8 & 6 & \\
\hline No & 8 & 9 & \\
\hline KRAS mutation & & & 0.458 \\
\hline Yes & 4 & 6 & \\
\hline No & 12 & 9 & \\
\hline
\end{tabular}

MAPK10, mitogen-activated protein kinase 10; TNM, tumor-nodemetastasis; EGFR, epidermal growth factor receptor.

addition, results from western blotting revealed that the ratio BAX/Bcl-2 was consistent with an increase in cell apoptosis (Fig. 9C and D).

\section{Discussion}

In the present study, propofol inhibited NSCLC cell proliferation and promoted NSCLC cell apoptosis by targeting the miR-21-5p/MAPK10 axis. A recent study reported the association between miR-21-5p and MAPK10 in breast cancer (24), and further confirmed the findings from the present study.

Propofol is a frequently used intravenous anesthetic agent (25). The clinical roles of propofol in cancer are as follows: i) Propofol exhibits less adverse effect on postoperative cognitive function from patients with lung cancer than sevoflurane (26); ii) propofol is applied to solve secondary cerebral lesions in patients with lung cancer (27); and iii) propofol-based total intravenous anesthesia is associated with prolonged recurrence-free survival and overall survival of patients who underwent tumor resection (28). Propofol has been demonstrated to decrease the LPS-induced apoptosis of the lung epithelial cell line BEAS-2B (29). In addition, it was reported that propofol serves crucial roles in lung cancer. 
A

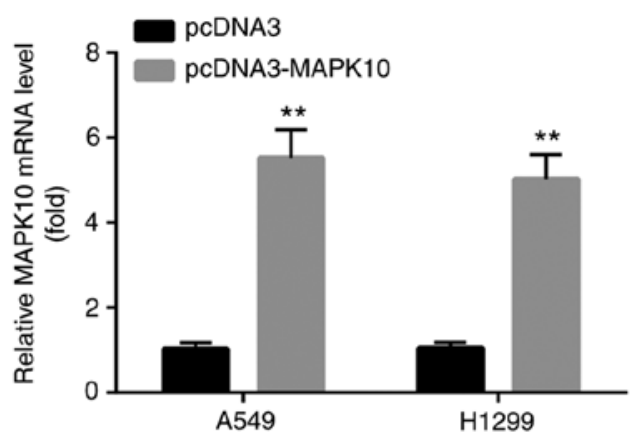

B
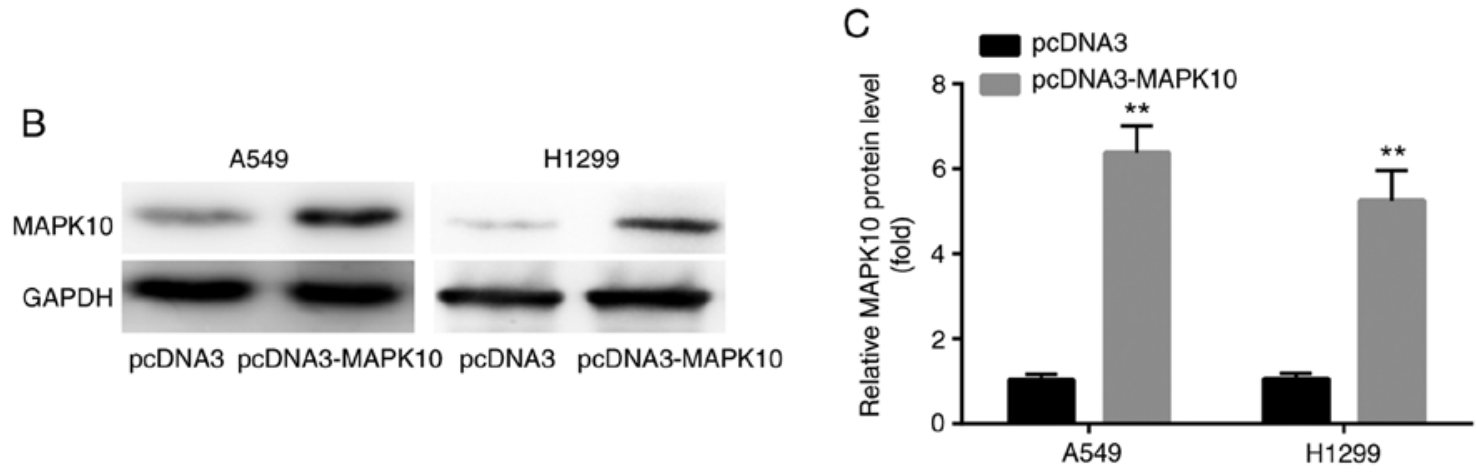

D

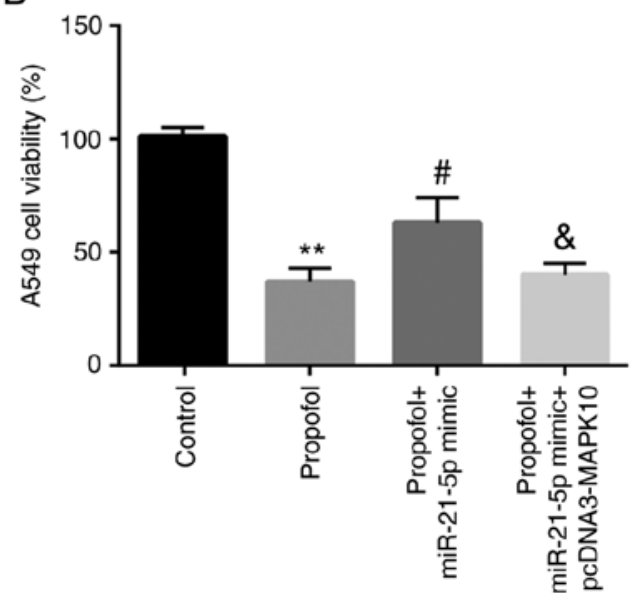

E

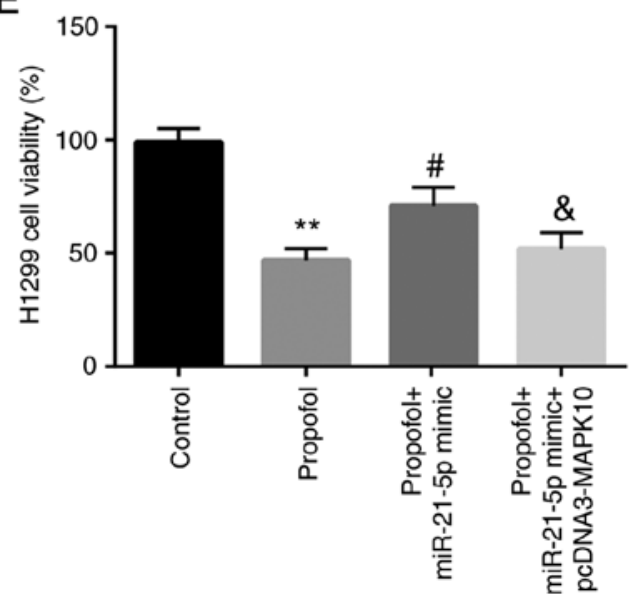

Figure 8. Propofol decreased A549 and H1299 cell viability via the miR-21-5p/MAPK10 axis. Compared with pcDNA3, pcDNA3-MAPK10 increased MAPK10 (A) mRNA and (B and C) protein expression in A549 and H1299 cells. (D and E) miR-21-5p mimic rescued propofol-induced decrease in cell viability, which was reversed by pcDNA3-MAPK10. ${ }^{* *} \mathrm{P}<0.01$, pcDNA3-MAPK10 vs. pcDNA3, propofol vs. control; ${ }^{*} \mathrm{P}<0.05$, propofol + miR-21-5p vs. propofol; ${ }^{\&} \mathrm{P}<0.05$, propofol + miR-21-5p + pcDNA3-MAPK10 vs. propofol + miR-21-5p. MAPK10, mitogen-activated protein kinase 10; miR, microRNA.

For example, propofol inhibits LPS-induced metastasis by decreasing hypoxia-inducible factor- $1 \alpha$ expression in NSCLC (30). In addition, propofol induces cell apoptosis by increasing the expression level of p53 upregulated modulator of apoptosis in NSCLC (31). It has also been demonstrated that propofol decreases the expression of the inflammatory factor matrix metalloproteinase 9 and the cognitive impairment in patients undergoing lung cancer resection (32). Consistently, the present study demonstrated that propofol inhibited NSCLC cell proliferation and promoted NSCLC cell apoptosis.

miRNAs are novel biomarkers for NSCLC (33). Recent studies described a novel therapeutic strategy based on miRNAs for patients with NSCLC (34). For example, miR-1298 suppresses tumor progression in NSCLC (35). In addition, the inhibition of miR-425 suppresses cell proliferation, migration and apoptosis in NSCLC (36), and miR-421 predicts the poor survival of patients with NSCLC (37). Propofol also inhibits the progression of NSCLC by regulating the expression level of some miRNAs, including miR-372 (13), miR-1284 (14) and miR-486 (15). As an important oncogene in NSCLC, a higher miR-21-5p level is associated with recurrence (38), tumor stage (39) and poor overall survival (40) of patients with NSCLC. The link between Fpropofol and miR-21 has been reported in several diseases, but not in NSCLC. For example, propofol suppresses breast cancer cell proliferation and EMT by inhibiting miR-21 expression (41). In addition, propofol has been reported to inhibit pancreatic cancer cell proliferation and invasion by decreasing miR-21 expression level (42). The decrease in miR-21 expression is associated with propofol-induced neurotoxicity in human stem cell-derived neurons (43). The present study demonstrated that propofol inhibited miR-21-5p expression in NSCLC cell lines. 
A

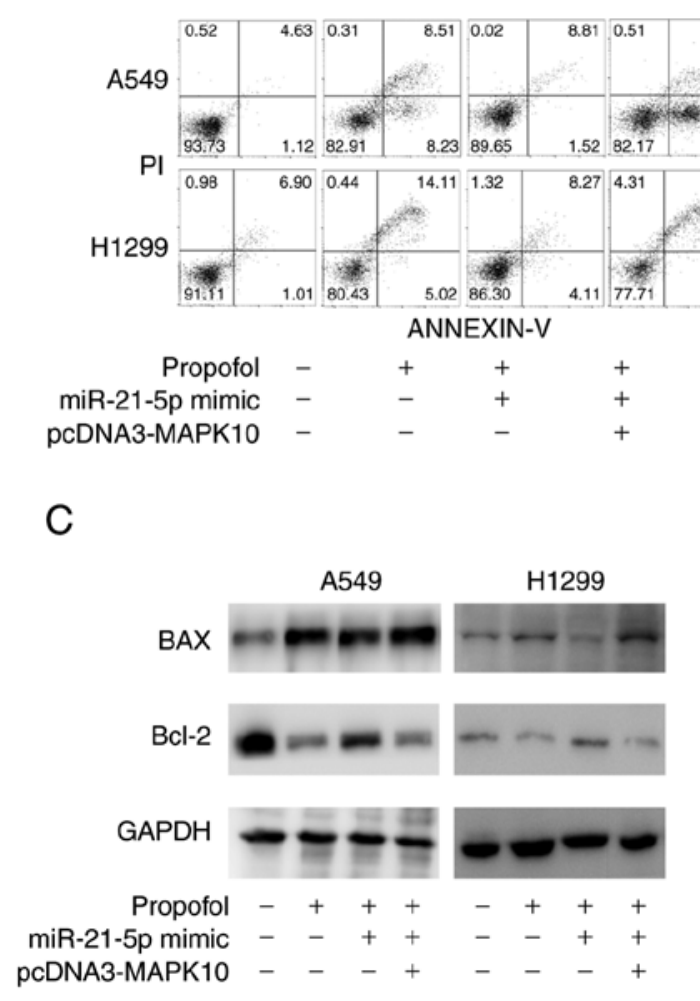

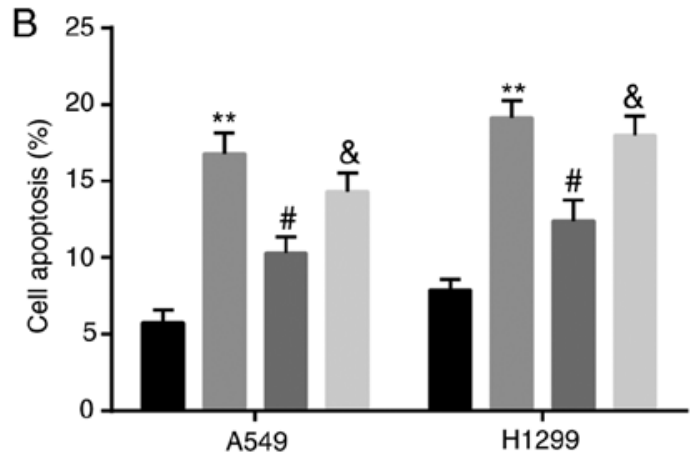

Propofol -++++++ miR-21-5p mimic - -++-++ pcDNA3-MAPK10 - $-\quad-+\quad-\quad-\quad-+$

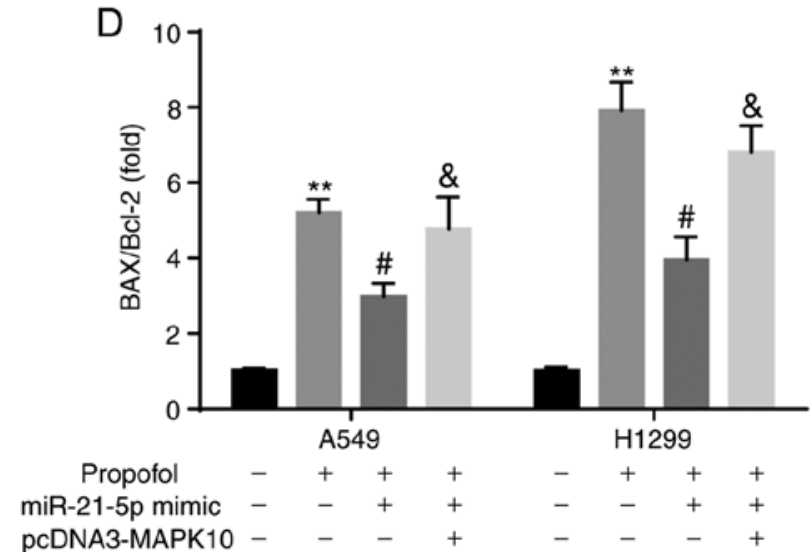

Figure 9. Propofol induced cell apoptosis by miR-21-5p/MAPK10 axis in A549 and H1299 cells. (A and B) Results from flow cytometry demonstrated that miR-21-5p mimic rescued propofol-induced cell apoptosis, which was reversed by pcDNA3-MAPK10. (C and D) Results from western blotting showed that miR-21-5p mimic rescued propofol-induced upregulation of BAX and downregulated Bcl-2, which were reversed by pcDNA3-MAPK10. ** $<0.01$, propofol vs. control; ${ }^{\text {"}} \mathrm{P}<0.05$, propofol + miR-21-5p vs. propofol; ${ }^{\&} \mathrm{P}<0.05$, propofol + miR-21-5p + pcDNA3-MAPK10 vs. propofol + miR-21-5p. miR, microRNA.

miRNAs function by targeting mRNAs (11). MAPK10 is an important pro-apoptotic gene (20). MAPK10 has been demonstrated to function as a novel epigenetic marker for chromophobe kidney cancer (44). Furthermore, MAPK10, which is targeted by miR-27a-3p, also serves a promotional role in nasopharyngeal carcinoma (22). In addition, MAPK10, which is targeted by miR-29b, is involved in ovarian carcinoma (45). However, to the best of our knowledge, there is no study on the link between NSCLC and MAPK10, propofol and MAPK10 or miR-21-5p and MAPK10 in NSCLC. In addition, the association between propofol and MAPK10 has not been reported in other diseases. The present study first verified that propofol increased MAPK10 expression, which was decreased in NSCLC cell lines, and that miR-21-5p targeted 3'-UTR of MAPK10.

Resistance to cell apoptosis contributes to the progression of NSCLC (46). For example, Acetyl-11-Keto- $\beta$-Boswellic acid has some anti-cancer effects by stimulating NSCLC apoptosis (47), KCP10043F reduces NSCLC proliferation by inducing caspase-mediated apoptosis (48) and ASB16-AS1 promotes the progression of NSCLC by decreasing cell apoptosis (49). In addition, propofol was reported to induce cell apoptosis by regulating the miR-21-5p/MAPK10 axis in NSCLC cell lines. In conclusion, the present study demonstrated that miR-21-5p and MAPK10 were associated with propofol-induced inhibition of NSCLC.

\section{Acknowledgements}

Not applicable.

\section{Funding}

No funding was received.

\section{Availability of data and materials}

All the data generated or analyzed during the current study are available from the corresponding author on reasonable request.

\section{Authors' contribution}

XW and GX performed the experiments. XW, XL and GX analyzed the data. XL designed the experiments and prepared the manuscript. All authors read and approved the final manuscript.

\section{Ethics approval and consent to participate}

The present study was approved by the Ethical Committee of People's Hospital of Xinjiang Uygur Autonomous Region. All patients provided written informed consent. 


\section{Patient consent for publication}

Not applicable.

\section{Competing interests}

The authors declare that they have no competing interests.

\section{References}

1. Siegel RL, Miller KD and Jemal A: Cancer statistics, 2017. CA Cancer J Clin 67: 7-30, 2017.

2. Meza R, Meernik C, Jeon J and Cote ML: Lung cancer incidence trends by gender, race and histology in the United States, 1973-2010. PLoS One 10: e0121323, 2015.

3. Forde PM and Ettinger DS: Targeted therapy for non-small-cell lung cancer: Past, present and future. Expert Rev Anticancer Ther 13: 745-758, 2013.

4. Pei K, Zhu JJ, Wang CE, Xie QL and Guo JY: MicroRNA-185-5p modulates chemosensitivity of human non-small cell lung cancer to cisplatin via targeting ABCC1. Eur Rev Med Pharmacol Sci 20: 4697-4704, 2016.

5. Johnson KN, Gooden G, Gonzalez P, Sepulveda M, Gorgol L, Petricoin EF, Pierobon M, Byron S, Glen J, Ahluwalia M, et al: BM-15 targeting MEK is a novel and effective treatment strategy of lung CNS metastasis. Neuro Oncol 16 (Suppl 5): v35, 2014.

6. Gholipour Baradari A, Firouzian A, Zamani Kiasari A, Aarabi M, Emadi SA, Davanlou A, Motamed N and Yousefi Abdolmaleki E: Effect of etomidate versus combination of propofol-ketamine and thiopental-ketamine on hemodynamic response to laryngoscopy and intubation: A randomized double blind clinical trial. Anesth Pain Med 6: e30071, 2016.

7. Huang $\mathrm{X}$, Teng $\mathrm{Y}$, Yang $\mathrm{H}$ and Ma J: Propofol inhibits invasion and growth of ovarian cancer cells via regulating miR-9/NF-kB signal. Braz J Med Biol Res 49: e5717, 2016.

8. Ecimovic P, Murray D, Doran P and Buggy DJ: Propofol and bupivacaine in breast cancer cell function in vitro-role of the NET1 gene. Anticancer Res 34: 1321-1331, 2014.

9. Xu YJ, Li SY, Cheng Q, Chen WK, Wang SL, Ren Y and Miao CH: Effects of anaesthesia on proliferation, invasion and apoptosis of LoVo colon cancer cells in vitro. Anaesthesia 71: $147-154,2016$.

10. Zhang J, Zhang D, Wu GQ, Feng ZY and Zhu SM: Propofol inhibits the adhesion of hepatocellular carcinoma cells by upregulating microRNA-199a and downregulating MMP-9 expression. Hepatobiliary Pancreat Dis Int 12: 305-309, 2013.

11. Garzon R, Calin GA and Croce CM: MicroRNAs in cancer. Annu Rev Med 60: 167-179, 2009.

12. Bartel DP: MicroRNAs: Genomics, biogenesis, mechanism, and function. Cell 116: 281-297, 2004.

13. Sun $\mathrm{H}$ and Gao D: Propofol suppresses growth, migration and invasion of A549 cells by down-regulation of miR-372. BMC Cancer 18: 1252, 2018.

14. Liu WZ and Liu N: Propofol inhibits lung cancer A549 cells growth and epithelial-mesenchymal transition process by upregulation of microRNA-1284. Oncol Res 27: 1-8, 2018.

15. Yang N, Liang Y, Yang P, Yang T and Jiang L: Propofol inhibits lung cancer cell viability and induces cell apoptosis by upregulating microRNA-486 expression. Braz J Med Biol Res 50 e5794, 2017.

16. Cserni G, Chmielik E, Cserni B and Tot T: The new TNM-based staging of breast cancer. Virchows Arch 472: 697-703, 2018.

17. Cancer Genome Atlas Research Network; Weinstein JN, Collisson EA, Mills GB, Shaw KR, Ozenberger BA, Ellrott K, Shmulevich I, Sander C and Stuart JM: The cancer genome atlas pan-cancer analysis project. Nat Genet 45: 1113-1120, 2013.

18. Tang Z, Li C, Kang B, Gao G, Li C and Zhang Z: GEPIA: A web server for cancer and normal gene expression profiling and interactive analyses. Nucleic Acids Res 45: W98-W102, 2017

19. Livak KJ and Schmittgen TD: Analysis of relative gene expression data using real-time quantitative PCR and the 2(-Delta Delta C(T)) method. Methods 25: 402-408, 2001.

20. Yang DD, Kuan CY, Whitmarsh AJ, Rincón M, Zheng TS Davis RJ, Rakic P and Flavell RA: Absence of excitotoxicity-induced apoptosis in the hippocampus of mice lacking the Jnk3 gene. Nature 389: 865-870, 1997.
21. Ying J, Li H, Cui Y, Wong AH, Langford C and Tao Q Epigenetic disruption of two proapoptotic genes MAPK10/JNK3 and PTPN13/FAP-1 in multiple lymphomas and carcinomas through hypermethylation of a common bidirectional promoter. Leukemia 20: 1173-1175, 2006.

22. Li L and Luo Z: Dysregulated miR-27a-3p promotes nasopharyngeal carcinoma cell proliferation and migration by targeting Mapk10. Oncol Rep 37: 2679-2687, 2017.

23. Ulivi P, Petracci E, Marisi G, Baglivo S, Chiari R, Billi M, Canale M, Pasini L, Racanicchi S, Vagheggini A, et al: Prognostic role of circulating miRNAs in early-stage non-small cell lung cancer. J Clin Med 8: E131, 2019.

24. Xie Y, Liu Y, Fan X, Zhang L, Li Q, Li S, Wang H and Xiao Y: MicroRNA-21 promotes progression of breast cancer via inhibition of mitogen-activated protein kinase10 (MAPK10). Biosci Rep: Aug 2, 2019 (Epub ahead of print).

25. Vasileiou I, Xanthos T, Koudouna E, Perrea D, Klonaris C, Katsargyris A and Papadimitriou L: Propofol: A review of its non-anaesthetic effects. Eur J Pharmacol 605: 1-8, 2009.

26. Sun H, Zhang G, Ai B, Zhang H, Kong X, Lee WT, Zheng H, Yan T and Sun L: A systematic review: Comparative analysis of the effects of propofol and sevoflurane on postoperative cognitive function in elderly patients with lung cancer. BMC Cancer 19: $1248,2019$.

27. Gheorghita E, Pruna VM, Neagoe L, Bucur C, Cristescu C and Gorgan MR: Perioperative management of patients with lung carcinoma and cerebral metastases. Maedica (Buchar) 5: 28-33, 2010.

28. Yap A, Lopez-Olivo MA, Dubowitz J, Hiller J and Riedel B; Global Onco-Anesthesia Research Collaboration Group Anesthetic technique and cancer outcomes: A meta-analysis of total intravenous versus volatile anesthesia. Can J Anaesth 66: 546-561, 2019

29. Lv X, Zhou X, Yan J, Jiang J and Jiang H: Propofol inhibits LPS-induced apoptosis in lung epithelial cell line, BEAS-2B. Biomed Pharmacother 87: 180-187, 2017.

30. Yang N, Liang Y, Yang P and Ji F: Propofol suppresses LPS-induced nuclear accumulation of HIF-1 $\alpha$ and tumor aggressiveness in non-small cell lung cancer. Oncol Rep 37: 2611-2619, 2017.

31. Xing SG, Zhang KJ, Qu JH, Ren YD and Luan Q: Propofol induces apoptosis of non-small cell lung cancer cells via ERK1/2-dependent upregulation of PUMA. Eur Rev Med Pharmacol Sci 22: 4341-4349, 2018.

32. Wang G, Liu J, Gao J and Zheng X: Comparison of the effects of sevoflurane and propofol anesthesia on pulmonary function, MMP-9 and postoperative cognition in patients receiving lung cancer resection. Oncol Lett 17: 3399-3405, 2019.

33. Wojczakowski W, Kobylarek D, Lindner J, Limphaibool N and Kaczmarek M: MicroRNAs-novel biomarkers for malignant pleural effusions. Contemp Oncol (Pozn) 23: 133-140, 2019.

34. Li G, Fang J, Wang Y, Wang H and Sun CC: MiRNA-based therapeutic strategy in lung cancer. Curr Pharm Des 23: 6011-6018, 2018.

35. Du Z, Wu J, Wang J, Liang Y, Zhang S, Shang Z and Zuo W: MicroRNA-1298 is downregulated in non-small cell lung cancer and suppresses tumor progression in tumor cells. Diagn Pathol 14: 132, 2019

36. Jiang L, Ge W and Geng J: MiR-425 regulates cell proliferation, migration and apoptosis by targeting AMPH-1 in non-small-cell lung cancer. Pathol Res Pract 215: 152705, 2019.

37. Duan FG, Wang MF, Cao YB, Dan Li, Li RZ, Fan XX, Khan I, Lai HL, Zhang YZ, Hsiao WW, et al: MicroRNA-421 confers paclitaxel resistance by binding to the KEAP1 3'UTR and predicts poor survival in non-small cell lung cancer. Cell Death Dis 10: 821, 2019.

38. Yang M, Shen H, Qiu C, Ni Y, Wang L, Dong W, Liao Y and Du J: High expression of miR-21 and miR-155 predicts recurrence and unfavourable survival in non-small cell lung cancer. Eur J Cancer 49: 604-615, 2013.

39. Abdollahi A, Rahmati S, Ghaderi B, Sigari N, Nikkhoo B, Sharifi $\mathrm{K}$ and Abdi M: A combined panel of circulating microRNA as a diagnostic tool for detection of the non-small cell lung cancer. QJM 112: 779-785, 2019.

40. Song F, Xuan Z, Yang X, Ye X, Pan Z and Fang Q: Identification of key microRNAs and hub genes in non-small-cell lung cancer using integrative bioinformatics and functional analyses. J Cell Biochem 121: 2690-2703, 2020. 
41. Du Q, Zhang X, Zhang X, Wei M, Xu H and Wang S: Propofol inhibits proliferation and epithelial-mesenchymal transition of MCF-7 cells by suppressing miR-21 expression. Artif Cells Nanomed Biotechnol 47: 1265-1271, 2019.

42. Liu Z, Zhang J, Hong G, Quan J, Zhang L and Yu M: Propofol inhibits growth and invasion of pancreatic cancer cells through regulation of the miR-21/slug signaling pathway. Am J Transl Res 8: 4120-4133, 2016

43. Twaroski DM, Yan Y, Olson JM, Bosnjak ZJ and Bai X: Down-regulation of microRNA-21 is involved in the propofol-induced neurotoxicity observed in human stem cell-derived neurons. Anesthesiology 121: 786-800, 2014.

44. Yoo KH, Park YK, Kim HS, Jung WW and Chang SG: Identification of MAPK10 as a novel epigenetic marker for chromophobe kidney cancer. Pathol Int 61: 52-54, 2011.

45. Dai F, Zhang Y and Chen Y: Involvement of miR-29b signaling in the sensitivity to chemotherapy in patients with ovarian carcinoma. Hum Pathol 45: 1285-1293, 2014

46. Liu G, Pei F, Yang F, Li L, Amin AD, Liu S, Buchan JR and Cho WC: Role of autophagy and apoptosis in non-small-cell lung cancer. Int J Mol Sci 18: E367, 2017.
47. Lv M, Shao S, Zhang Q, Zhuang X and Qiao T: Acetyl-11-Keto$\beta$-Boswellic acid exerts the anti-cancer effects via cell cycle arrest, apoptosis induction and autophagy suppression in non-small cell lung cancer cells. Onco Targets Ther 13: 733-744, 2020.

48. Lee JH, Lee HH, Ryu KD, Kim M, Ko D, Chung KS, Hassan AHE, Lee SH, Lee JY and Lee KT: KCP10043F represses the proliferation of human non-small cell lung cancer cells by caspase-mediated apoptosis via STAT3 inactivation. J Clin Med 9: E704, 2020.

49. Tan LJ, Liu JT, Yang M, Ju T and Zhang YS: LncRNA ASB16-AS1 promotes proliferation and inhibits apoptosis of non-small cell lung cancer cells by activating the Wnt $/ \beta$ catenin signaling pathway. Eur Rev Med Pharmacol Sci 24: 1870-1876, 2020.

This work is licensed under a Creative Commons Attribution-NonCommercial-NoDerivatives 4.0 International (CC BY-NC-ND 4.0) License. 